\title{
APLIKASI PUPUK BOKASHI PENGARUHNYA PADA MUTU KIMIA SAMBILOTO (ANDROGRAPHIS PANICULATA NESS) DAN AKTIVITAS EKSTRAKNYA DALAM MENURUNKAN KADAR KOLESTEROL DARAH
}

\author{
Sudarmi ${ }^{1)}$, Wiwik Darmini ${ }^{2)}$, Wartini $^{3)}$ \\ ${ }^{1)}$ Fakultas Pertanian ${ }^{2)}$ Fakultas Keguruan Dan IImu Pendidikan ${ }^{2)}$ Fakultas Kesehatan Masyarakat Universitas \\ Veteran Bangun Nusantara Sukoharjo \\ JI. Letjen S. Humardani No. 1 Sukoharjo, kode pos 57512, \\ Telp. (0271) 593156, Fax (0271) 591065, \\ Corresponding author Phone: 081802591402 E-mail: Sudarmi1959@yahoo.com
}

\begin{abstract}
ABSTRAK
Tujuan penelitian adalah mempelajari pengaruh pemupukan bokashi terhadap mutu simplisia dan kemampuan ekstrak sambiloto (Andrographis paniculata Ness) dalam menurunkan kadar kolesterol darah. Simplisia yang memenuhi standar mutu MMI (Materia Media Indonesia) digunakan sebagai bahan mengkaji kemampuan ekstrak sambiloto untuk penurunan kadar kolesterol darah. Metode penelitian adalah eksperimen menggunakan Rancangan Acak Lengkap (RAL) dengan 3 ulangan, 6 perlakuan dosis ekstrak sambiloto yaitu : Dosis 0 ekstrak sambiloto (kontrol normal, D0); kontrol positip kolesterol (D1); pembanding simvastatin 2mg/200 gr bb (D2); dosis $100 \mathrm{mg}$ sambiloto/200 gr bb (D3); dosis $200 \mathrm{mg}$ sambiloto/200 gr bb (D4) dan dosis $400 \mathrm{mg}$ sambiloto/200 gr bb (D5). Tikus yang diuji adalah tikus putih jantan galur Wistar berumur 2 bulan, berat badan \pm 200 gr. Analisis menggunakan Anova, dan uji lanjut menggunakan DMRT, a 5\%. Hasil penelitian menunjukan bahwa ekstrak sambiloto dosis $100 \mathrm{mg} / 200 \mathrm{gr} \mathrm{bb}, 200 \mathrm{mg} / 200 \mathrm{gr} \mathrm{bb} ; 400 \mathrm{mg} / 200 \mathrm{gr}$ bb dan pembanding simvastatin $2 \mathrm{mg} / 200$ gr bb semuanya dapat menurunkan kadar kolesterol total darah tikus yang dibuat hiperkolesterolemia. Perlakuan dosis $400 \mathrm{mg} / 200 \mathrm{gr}$ bb mempunyai kemapuan hampir sama dengan simvastatin dosis $2 \mathrm{mg} / 200 \mathrm{gr}$ bb dalam menurunkan kadar kolesterol total darah tikus yaitu sebesar $51 \%$, dengan pertimbangan resiko hipokolesterolemia.
\end{abstract}

Kata kunci : hiperkolesterolemia , kadar kolesterol darah, Pupuk bokashi, sambiloto

The Application of Bokashi Fertilizer to Effect on the Chemical Quality of Sambiloto (Andrographis paniculata Ness) and Extract Activity to Reduce Blood Cholesterol levels

\begin{abstract}
The objective of this research was to stydy the application of bokashi fertilizer on chemical quality and ability of sambiloto extract (Andrographis paniculata Ness) to reduce blood cholesterol levels.Simplicia which meets the MMI quality standad is used to reduce blood cholesterol levels. The experiment used of Randomized Completely Design arranged with tree replication and six treatment namely control normal (D0), control positip cholesterol (D1), simvastatin compare (D2), $100 \mathrm{mg}$ sambiloto/200 g bw (D3), $200 \mathrm{mg} / 200 \mathrm{~g}$ bw (D4) and $400 \mathrm{mg}$ sambiloto/200 $\mathrm{g}$ bw (D5). The result of this research indicated that twelve combinations treatments of simplisia sambiloto fulled quality standart MMI. The extract sambiloto reduced rat blood cholesterol levels at all doses treatment. It is interesting that the extract at dose $400 \mathrm{mg}$ sambiloto/200 $\mathrm{g}$ bw equally the effect to simvastatin 2 $\mathrm{mg} / 200 \mathrm{~g}$ bw, showed the capacity to redused blood cholesterol level $51 \%$, considering the risk of hypocholesterolemia.
\end{abstract}

Keywords: Bokashi fertilizer, blood cholesterol level, sambiloto extract 


\section{PENDAHULUAN}

Andrographis paniculata Ness (dikenal sebagai sambiloto di indonesia) juga dikenal sebagai raja pahit. Herba sambiloto dipakai sebagai bahan baku obat tradisional oleh masyarakat Indonesia terutama untuk menurunkan kadar kolesterol darah. Kolesterol merupakan salah satu penyebab penyakit jantung koroner (PJK). Penyakit jantung dewasa ini merupakan penyebab paling utama sakit dan kematian bangsa-bangsa industri maju (Ariantari dkk., 2010). Di Amerika Serikat, penyakit jantung merupakan penyebab utama kematian, yaitu kira-kira 37\%. Sekitar $88 \%$ dari angka tersebut, disebabkan karena penyakit jantung koroner (Ariantari dkk., 2010).

Kolesterol merupakan unsur penting dalam tubuh yang diperlukan untuk mengatur proses kimiawi di dalam tubuh, tetapi kolesterol dalam jumlah tinggi bisa menyebabkan terjadinya aterosklerosis yang akhirnya akan berdampak pada penyakit jantung koroner (Rahayu, 2005). Hiperkolesterolemia adalah suatu kondisi jumlah kolesterol darah melebihi batas normalnya.

Didunia kedokteran senyawa sinamaldehid yang merupakan turunan dari senyawa fenol diketahui memiliki sifat anti agregasi platelet dan sebagai vasodilator secara in vitro. Selain itu senyawa anti oksidan lain seperti tannin dan flavonoid juga diharapkan bisa menurunkan kadar kolesterol dengan cara melindungi LDL dari proses oksidasi sehingga dapat mencegah aterosklorosis (Azima, 2004)

Sambiloto (Andrographis paniculata Ness) merupakan salah satu dari sembilan obat tradisional yang diunggulkan untuk dikaji sampai tahap uji klinis (Widyawati, 2007). Menurut WHO, sekitar $65 \%$ dari penduduk Negara maju dan $80 \%$ dari penduduk Negara berkembang telah menggunakan obat herbal sebagai obat tradisional. Oleh karena itu perlu ditingkatkan mutu kimia sambiloto dengan meningkatkan kandungan bahan aktifnya. Untuk mengetahui mutu simplisia dilakukan pengukuran meliputi : kadar air, kadar sari air, kadar sari alkohol, kadar abu, kadar abu tak larut asam, kadar andrographolid. Kandungan kimia sambiloto cukup potensial yaitu : andrographolid, neoandrographolid, tannin, alkaloid, glikosida, flavonoid, yang semuanya merupakan hasil dari metabolit sekunder
(Yusron dan Januwati, 2004; Winarto, 2003), maka sambiloto dapat dimanfaatkan sebagai anti peritrik, anti hepatoksik, anti malaria, anti trombogenik, HIV, anti inflamasi, anti deman, antibiotik, anti diare, anti bengkak dan anti diabetes dan anti hiperkolesterolmia (Dalimartha, 2003; Yusron dan Januawati, 2004; Sembiring, 2006, Widowati, 2007; Fatmawati, 2008).

Obat hipolipidemia/hipokolesterolemia akan menimbulkan ketergantungan bagi penggunanya dan bila digunakan secara berkelanjutan obat ini akan mengakibatkan gangguan fungsi organ lain seperti fungsi ginjal, hati, dan paru-paru (Hicow, 2011). Adanya bahaya yang dapat ditimbulkan obat hipolipidemia maka diperlukan usaha untuk mencari alternatif lain yang lebih aman, misalnya penggunaan tanaman yang memiliki potensi hipolipidemia. Tanaman berpotensi hipolipidemia merupakan tanaman yang dapat menurunkan kadar lemak dalam darah karena kandungan senyawa aktif yang dimilikinya. Tanaman berpotensi hipolipidemia memiliki kandungan senyawa aktif seperti flavonoid, tannin, andrographolid yang berperan sebagai anti oksidan (Chris, 2008; Fatmawati, 2008). Tanaman berpotensi hipolipidemia yang memiliki kandungan senyawa antioksidan antara lain adalah sambiloto.

Khasiat tanaman sambiloto yang pahit ini telah banyak diteliti untuk penyembuhan berbagai penyakit. Tahun 2000 sambiloto telah diuji klinis untuk pengobatan HIV bahwa Andrographolide menghambat disregulasi siklus sel yang diinduksi HIV (Widyawati, 2007). Menurut Winarto (2003) ekstrak sambiloto dapat merusak sel trophocyt dan trophoblast, berperanan dalam kondensasi cytoplasma dari sel tumor dan menghancurkan inti sel kanker. Dilaporkan Widyawati (2007) telah mengobservasi efek komponen sambiloto terhadap nitric oxide, endothelin, cyclic guanosine monophosphate, lipid peroxide dan super-oxide dismutase, pada model kelinci percobaan yang memiliki aterosklerotik dengan cara memberi diet tinggi kolesterol. Dari penelitian tersebut dikatakan bahwa sambiloto memiliki efek antioksidan, menjaga fungsi endothelial, dan mempertahankan keseimbangan nitric oxide/endothelin yang dapat membantu mengendalikan kadar kolesterol darah. 
Penelitian pemberian ekstrak daun sambiloto selama 21 dan 28 hari dengan dosis $2,1 \mathrm{~g} / \mathrm{kg}$ bb ternyata dapat menurunkan kadar kolesterol total, HDL, LDL dan trigliserida hingga mendekati kadar kolesterol normal /kontrol (Fatmawati, 2008).

Berbagai pengujian beberapa tanaman untuk menurunkan kadar kolesterol darah yang telah dilakukan antara lain : Sari perasan buah nanas $100 \%, 80 \%$ dan $60 \%$ dapat menurunkan kadar kolesterol total secara berurutan sebesar 152,$59 ; 144,74 ; 131,65 \mathrm{mg} / \mathrm{dl}$ dan ekstrak akar meniran dosis $4 \mathrm{mg} / 200 \mathrm{gr}$ bb dapat menurunkan kadar kolesterol total 11,59\% (Fahri, dkk., 2005). Perlu diuji ekstrak sambiloto untuk menurunkan kadar kolesterol.

Telah dilakukan uji toksikologi pada hewan coba dan menunjukkan bahwa andrographolide dan senyawa lain pada sambiloto memiliki toksisitas yang sangat rendah. Pada mencit yang diberi ekstrak sambiloto secara oral $(10 \mathrm{~g} / \mathrm{kg} \mathrm{bb})$ sekali sehari selama 7 hari, tidak ada tikus yang mati (Chung, 1979 dalam Widyawati, 2007). Jantung, ginjal, hati dan limpa dijumpai dalam keadaan normal, maka sambiloto aman sebagai obat herbal (Astuti, dkk. 2000).

Pada penelitian ini telah dilakukan pengujian ekstrak sambiloto terhadap tikus Rattus norvegicus galur wistar yang telah dikondisikan hiperkolesterolemia dengan pemberian pakan standart (AD II) yang ditambah kuning telor dan minyak babi.

Berdasarkan uraian tersebut di atas, maka dirumuskan permasalahan sebagai berikut: Apakah simplisia sambiloto yang diuji memenuhi standart mutu MMI dan Apakah aktivitas ekstrak sambiloto dapat menurunkan kadar kolesterol darah tikus yang dikondisikan hiperkolesterolemia?. Tujuan penelitian ini yaitu menentukan mutu kimia simplisia sambiloto dan Mengkaji Dosis ekstrak sambiloto untuk menurunkan kadar kolesterol darah tikus yang dikondisikan hiperkolesterolemia.

\section{METODE PENELITIAN}

Penelitian dilaksanakan bulan Maret 2018 s/d Oktober 2018 di Laboratorium Fakultas Kedokteran UNS Surakarta. Metode penelitian adalah eksperimen, dengan Rancangan Acak Lengkap (RAL) 3 ulangan, 6 perlakuan dosis yaitu : 1) $D 0=$ kontrol normal; 2) $D 1=$ kontrol positip kolesterol; 3) D2= kontrol pembanding simvastatin $2 \mathrm{mg} / 200 \mathrm{gr} \mathrm{bb}$; 4) D3=dosis 100 $\mathrm{mg}$ sambiloto/200 gr bb; 5) D4=dosis $200 \mathrm{mg}$ sambiloto/200 gr bb; 6) D5= dosis $400 \mathrm{mg}$ sambiloto/200 gr bb. Hewan uji yang digunakan adalah tikus putih jantan galur Wistar berumur 2 bulan, berat badan $\pm 200 \mathrm{gr}$ dalam kondisi sehat (Kusumawati, 2004). Hasil dianalisis menggunakan Analisis of Variance (Anova) dan uji lanjut menggunakan DMRT, alpha 5\% (Anonim, 2007; Christensen, 1996 ).

\section{HASIL DAN PEMBAHASAN}

\section{Hasil penetapan mutu kimia simplisia sambiloto}

Berdasar hasil analisis mutu kimia simplisia sambiloto pada 12 kombinasi perlakuan tersaji pada tabel 1. Dari tabel 1. bahwa hasil uji kimia simplisia sambiloto, semua perlakuan memenuhi standar mutu MMI (Materia Media Indonesia) sehingga dapat digunakan sebagi bahan uji penurunan kadar kolesterol darah. 
Tabel 1. Hasil pengujian mutu kimia simplisia Sambiloto (Andrographis paniculata Ness)

\begin{tabular}{|c|c|c|c|c|c|}
\hline Perlakuan & $\begin{array}{c}\text { Kadar Air } \\
(\%)\end{array}$ & $\begin{array}{c}\text { Kadar Abu } \\
(\%)\end{array}$ & $\begin{array}{c}\text { Kadar Abu tak } \\
\text { Larut Asam } \\
(\%)\end{array}$ & $\begin{array}{c}\text { Kadar Sari } \\
\text { Air (\%) }\end{array}$ & $\begin{array}{c}\text { Kadar Sari } \\
\text { Alkohol (\%) }\end{array}$ \\
\hline B1T0 & 8.5 & 7.42 & 1.1 & 19 & 19.77 \\
\hline B1T1 & 9.3 & 5.43 & 1.4 & 29 & 27.11 \\
\hline B1T2 & 7.7 & 7.53 & 2.1 & 18 & 21.96 \\
\hline B2T0 & 8.7 & 7.4 & 1.7 & 19 & 14.08 \\
\hline B2T1 & 8,9 & 9.67 & 2.0 & 21 & 12.9 \\
\hline B2T2 & 8.1 & 10.10 & 1.7 & 29 & 15.64 \\
\hline B3T0 & 9.5 & 11.01 & 1.4 & 21 & 11.34 \\
\hline B3T1 & 9.6 & 6.85 & 1.1 & 18 & 16.29 \\
\hline B3T2 & 7.8 & 9.92 & 2.1 & 38 & 17.85 \\
\hline B4T0 & 8.6 & 10.20 & 1.7 & 21 & 14.39 \\
\hline B4T1 & 8.0 & 11.04 & 2.1 & 22 & 11.40 \\
\hline B4T2 & 9.0 & 10.25 & 1.4 & 23 & 12.41 \\
\hline $\begin{array}{l}\text { Standar } \\
\text { MMI }\end{array}$ & Maks 10 & Maks 12 & Maks 2.2 & Min 18 & Min 9.7 \\
\hline $\begin{array}{r}\text { Keterangan: } \\
\text { MMI Ketetap } \\
\mathrm{B}_{1}: \text { dos } \\
\mathrm{B}_{2}: \text { dos } \\
\mathrm{B}_{3}: \text { dosi } \\
\mathrm{B}_{4}: \text { dosi }\end{array}$ & $\begin{array}{l}\text { mutu Mate } \\
\text { bokashi } 0 \\
\text { bokashi } 5 \mathrm{t} \\
\text { bokashi } 10 \\
\text { bokashi } 15\end{array}$ & $\begin{array}{l}\text { Medika Indor } \\
\text { r } \\
\text { n/ha } \\
\text { n/ha }\end{array}$ & $\begin{array}{l}\text { esia } \\
\mathrm{T}_{0} \text { ( saat tanam } \\
\mathrm{T}_{1}(1 \text { minggu } \mathrm{s} \\
\mathrm{T}_{2}(2 \text { minggu se }\end{array}$ & $\begin{array}{l}\text { elah tanam) } \\
\text { elah tanam) }\end{array}$ & \\
\hline
\end{tabular}

\section{Hasil Uji Penurunan kadar kolesterol total darah.}

Hasil analisis of variance dengan Uji $\mathrm{F}$ taraf $5 \%$ kadar kolesterol total $(\mathrm{mg} / \mathrm{dl})$ tikus sebelum maupun sesudah pemberian pakan tinggi lemak dan pemberian bahan uji sambiloto, menunjukkan bahwa uji kadar kolesterol sebelum pemberian pakan tinggi lemak berbeda tidak nyata, sedang kada kolesterol sesudah pemberian pakan tinggi lemak selama 7 dan 14 hari menunjukkan perbedaan nyata. Demikian juga kadar kolesterol setelah pemberian bahan uji sambiloto selama 7 dan 14 hari menunjukkan perbedaan nyata. Untuk perlakuan yang menunjuukan perbedaan nyata diuji lanjut dengan uji DMRT alpha 5\%, hasilnya dapat dilihat pada tabel2. 
Tabel 2. Rerata kadar kolesterol darah tikus pada hari ke 7 hari ke 14 dan 21, hari ke 28 dan 35.

\begin{tabular}{|c|c|c|c|c|c|}
\hline Perlakuan & \multicolumn{5}{|c|}{ Kadar kolesterol total darah (mg/dl) } \\
\hline & $\begin{array}{l}\text { Adaptasi } 1 \\
\text { Minggu } \\
\text { (hari ke 7) }\end{array}$ & $\begin{array}{l}\text { Pakan tinggi } \\
\text { lemak (hari } \\
\text { ke } 14 \text { ) }\end{array}$ & $\begin{array}{l}\text { Pakan tinggi } \\
\text { lemak (hari } \\
\text { ke 21) }\end{array}$ & $\begin{array}{l}\text { Bahan uiji } \\
\text { sambiloto } \\
\text { (hari ke 28) }\end{array}$ & $\begin{array}{l}\text { Bahan uji } \\
\text { sambiloto } \\
\text { (hari ke35) }\end{array}$ \\
\hline D0 & $136.0 \mathrm{a}$ & 142.0 a & 156.7 a & $165.3 \mathrm{a}$ & $5.076 \mathrm{a}$ \\
\hline D1 & $158.3 \mathrm{a}$ & $191.3 \mathrm{~b}$ & 248.7 & $268.0 \mathrm{c}$ & $5.699 \mathrm{c}$ \\
\hline D2 & 154.3 a & $174.7 \mathrm{~b}$ & $236.3 \mathrm{~b}$ & $179.3 \mathrm{~b}$ & 5.162 a \\
\hline D3 & $145.0 \mathrm{a}$ & $183.3 \mathrm{~b}$ & $262.3 \mathrm{~b}$ & $218.0 \mathrm{~b}$ & $5.401 \mathrm{~b}$ \\
\hline D4 & $136.3 \mathrm{a}$ & $199.7 \mathrm{c}$ & 249.7 & $204.3 \mathrm{~b}$ & $5.257 \mathrm{~b}$ \\
\hline D5 & $137.0 \mathrm{a}$ & 181.7 & 297.0 & $188.3 \mathrm{~b}$ & $5.153 \mathrm{a}$ \\
\hline
\end{tabular}

Keterangan : Angka -angka dalam kolom sama yang diikuti huruf sama menunjukkan berbeda tidak nyata pada uji DMRT alpha $5 \%$.

\section{Pembahasan}

Dari tabel 1, hasil analisis mutu kimia simplisia sambiloto pada 12 kombinasi perlakuan, ternyata semua ekstrak sambiloto memenuhi standart mutu yang telah ditetapkan MMI/Materia Medika Indonesia (Dep Kes,1996). sehingga dapat digunakan sebagi bahan uji penurunan kadar kolesterol darah. Mutu simplisia dipengaruhi oleh ketersediaan air, ketersediaan unsur hara, umur tanaman, cara panen dan penanganan pasca panen (Gupta, 1991 dalam Yusron dkk, 2004). Didukung Muliawati (2002) dan Sugiarso (2004) bahwa kuantitas bahan aktif sambiloto sangat dipengaruhi ketersediaan air tanah, jenis tanah, suhu udara dan intensitas cahaya matahari yang semuanya akan mempengaruhi proses produksi metabolit sekunder tanaman obat.

Hasil pemeriksaan kadar kolesterol darah sebelum pemberian pakan tinggi kolesterol dalam kisaran normal dan bervariasi homogen $( \pm 152 \mathrm{mg} / \mathrm{dl})$, ini hampir stabil untuk perlakuan kelompok kontrol normal (D0) sampai akhir penelitian, sehingga layak untuk digunakan sebagai kadar kolesterol darah awal penelitian. Kadar kolesterol darah setelah pemberian pakan tinggi lemak selama 1 minggu (hari ke 14) menunjukkan perbedaan nyata antara kelompok kontrol normal (D0) dengan kelompok lain yang diberi pakan tinggi lemak (D1- D5) terjadi peningkatan kadar kolesterol tetapi belum terjadi hiperkolesterolemia. Maka pemberian pakan tinggi kolesterol dilanjutkan sampai hari ke 21 (14 hari), ternyata tikus sudah hiperkolesterolemia. Selanjutnya tikus diberi bahan uji sambiloto sampai 14 hari, karena pemberian bahan uji sambiloto selama 7 hari, kadar kolesterol rata-rata masih di atas ambang normal (> $200 \mathrm{mg} / \mathrm{dl}$ ). Selanjutnya pengujian statistik kadar kolesterol darah pada hari pengamatan ke 28 (pemberian bahan uji sambiloto selama 1 minggu) dengan uji DMRT alpha $5 \%$ bahwa D0 berbeda nyata dengan D2, D3, D4 dan D5. Kelompok kontrol positip (D1: yaitu pemberian pakan tinggi lemak tanpa diberi bahan uji) juga menunjukkan perbedaan yang nyata dengan kelompok kontrol normal (D0) maupun yang diberi bahan uji sambiloto, dan simvastatin (D2, sebagai pembanding). Hewan coba pada perlakuan kontrol positip (D1: pemberian pakan tinggi lemak tanpa bahan uji sampai akhir pengamatan) juga menunjukkan peningkatan berat badan. Sedang antar perlakuan D3, D4 dan D5 hasil pengujian kadar kolesterol berbeda tidak nyata. Hal ini menunjukkan bahwa pemberian bahan uji sambiloto selama 1 minggu, walaupun sudah mampu menurunkan kadar kolesterol tetapi kadar kolesterol masih berada diambang batas hiperkolesterolemia. Pengujian statistik kadar kolesterol darah pada hari pengamatan ke 35 (pemberian bahan uji sambiloto selama 2 minggu) dengan uji DMRT alpha 5\% bahwa 
Kelompok kontrol positip D1( hewan coba diberi pakan tinggi lemak sampai akhir pengamatan) menunjukkan perbedaan sangat nyata dengan perlakuan D0, D2, D5 dan menunjukkan perbedaan nyata dengan perlakuan D3 dan D4. Kelompok perlakuan D3 (pemberian bahan uji sambiloto $100 \mathrm{gr} / 200 \mathrm{gr}$ bb) dan D4 (pemberian bahan uji sambiloto $200 \mathrm{mg} / 200 \mathrm{bb}$ ) berbeda tidak nyata. Kelompok perlakuan D3 dan D4 mempunyai kemampun hampir sama dalam menurunkan kadar kolesterol hewan coba sebesar $(42,02 \%)$. Kelompok kontrol normal (D0); kelompok simvastatin (D2: hewan coba di beri bahan uji simvastatin $2 \mathrm{mg} / \mathrm{dl}$ sebagai pembanding); dan kelompok perlakuan D5 ( pemberian bahan uji sambiloto $400 \mathrm{mg} / 200 \mathrm{gr}$ bb) berbeda tidak nyata. Hal ini berarti ekstrak sambiloto dosis $400 \mathrm{mg} / 200 \mathrm{gr}$ bb dan uji pembanding simvastati $2 \mathrm{mg} / 200 \mathrm{gr}$ bb mempunyai kemampuan hampir sama dalam menurunkan kadar kolesterol total darah hewan coba sebesar $(51,14 \%)$ tetapi perlu dipertimbangkan resiko hipokolesterolemia. Widyawati (2007) mengatakan, bahwa penurunan kadar kolesterol bisa disebabkan oleh adanya berbagai kandungan zat aktif dalam ekstrak sambiloto yang memiliki efek antioksidan, menjaga fungsi endothelial, dan mempertahankan keseimbangan nitric oxide/endothelin yang dapat membantu mengendalikan kadar kolesterol darah. Selain itu penurunan kadar kolesterol dimungkinkan adanya kandungan serat dan vitamin dari pakan standar AD II yang digunakan. Menurut Budiyono dan Chandra (2013), penurunan kadar kolesterol dan trigliserida oleh serat dilakukan dengan cara mengikat asam lemak bebas serta kolesterol dalam bentuk asam empedu ketika dalam saluran pencernaan, kemudian diekskresikan bersama feces. Serat juga difermentasikan oleh mikroflora di dalam usus, sehingga menghasilkan asam asetat, propionate dan butirat yang dapat menghambat sintesis kolesterol.

\section{KESIMPULAN}

Berdasar penelitian yang telah dilakukan maka dapat diambil kesimpulan :
1) Hasil uji kimia simplisia sambiloto, semua perlakuan memenuhi standar mutu MMI (Materia Medika Indonesia) sehingga dapat digunakan sebagi bahan uji penurunan kadar kolesterol darah.

2) Ekstrak sambiloto dosis $100 \mathrm{mg} / 200 \mathrm{gr} \mathrm{bb}$; $200 \mathrm{mg} / 200 \mathrm{gr} \mathrm{bb} ; 400 \mathrm{mg} / 200 \mathrm{gr}$ bb dan pembanding simvastatin $2 \mathrm{mg} / 200 \mathrm{gr}$ bb semuanya dapat menurunkan kadar kolesterol total darah hewan coba dan dosis $400 \mathrm{mg} / 200 \mathrm{gr}$ bb mempunyai kemapuan hampir sama dengan dosis simvastatin $2 \mathrm{mg} / 200 \mathrm{gr}$ bb dalam menurunkan kadar kolesterol total darah hewan coba sebesar 51\%, tetapi perlu dipertimbangkan resiko hipokolesterolemia.

\section{UCAPAN TERIMA KASIH}

Terima kasih kepada Direktorat Riset dan Pengabdian Masyarakat, Direktorat Jenderal Penguatan Riset dan Pengembangan. Kementerian Riset, Teknologi dan Pendidikan Tinggi Sesuai dengan Kontrak Penelitian Tahun 2018.

\section{DAFTAR PUSTAKA}

Azima, F. 2004. Aktivitas Antioksidan dan Antiagregasi Platelet Ekstrak Grasisa vera (Cinnamomun burnanni Nees Ex Blume) Serta Potensinya dalam Pencegahan Aterosklerosis pada Kelinci. Disertasi. Institut Pertanian Bogor. (Disertasi)

Ariantari, N., P., Yowani, S. C., Swastini, D. A. 2010. Uji Aktivitas Penurunan Kolesterol Produk Madu Herbal yang Beredar di Pasaran Pada Tikus Putih Dietv Lemak Tinggi Jurnal Kimia 4 (1) : 15-19.(Pustaka jurnal)

Astuti, Chozin dan Winarno, 2000. Gambaran Hispatologi Organ Hati dan Ginjal Setelah Pemberian Ekstrak Sambiloto (Andrographis paniculata Ness). Balai 
Penelitian Tanaman Obat, PUSLITBANG DEPKES RI.

Budiyono, W. dan Candra, A. Perbedaan Kadar Kolesterol Total dan Trigliserida Sebelum dan Setelah Pemberian Daun Cincau Hijau (Premna oblongifolia Merr) pada Tikus Dislipidemia. Journal of Nutrition College 2 (1) : 118 - 125. (Pustaka Jurnal)

Christensen, R. 1996. Analysis of variance, Design and Regression : Applied Statistical Methods. Chapman and Hall. London. (Pustaka buku)

Dalimartha, S. 2003. Tumbuhan Obat. Penebar Swadaya. Jakarta. (Pustaka buku) Dep. Kesehatan, 1996. Materia Medika Indonesia. DepKes RI. (Pustaka buku)

Fahri,C., Sutarno, S. Listyawati. 2005. Kadar Glukosa dan Kolesterol Total darah Tikus Putih Hiperglikemik Setelah Pemberian Ekstrak Metanol Akar Meniran. Biofarma 3(1) : 1-6. Februari 2005 ISSN: 1693-2242. (pustaka Jurnal).

Fatmawati, 2008. Pengaruh Lama Pemberian Ekstrak Sambiloto Terhadap KadarKolesterol, LDL, HDL dan Trigliserida Darah Tikus Diadetes. http://lib.uin malang ac.id (informasi dari internet).

Hicow. 2011. Mengurangi Tingkat Kolesterol Menggunakan Zocor. http:// id. hicow.com/statin/low-densitylipoprotein/simvastatin-2791071.html. Diakses 30 Januari 2012 (Informasi dari Internrt)

Kusumawati, D. 2004. Bersahabat dengan Hewan Coba. Yogyakarta. Gadjahmada University Press. (Pustaka buku)

Nuryati, S.2004. Sambiloto Tanaman Obat Untuk Demam dan Asma. http://www.beritabumi.or.id

\section{Desember 2007]. (informasi dari Internet)}

Rahayu, T. 2005. Kadar Kolesterol Darah Tikus Putih (Rattus norvegicus L) setelah Pemberian Cairan Kombucha Per-Oral. Jurnal Penelitian Sains dan Teknologi FKIP UMS 6 (2): 85 - 100. (Pustaka Jurnal)

Sembiring, B.S., Feri, M dan M. Januawati. 2006.Pengaruh Nisbah Bahan dengan Pelarut dan Lama Ekstraksi terhadap Mutu Ekstrak Sambiloto (Andrographis paniculata Ness.). Pros. Seminar Nasional dan pameran Tumbuhan Obat Indonesia XXVIII. Pokjanas Tumbuhan Obat Indonesia. 157-163. (Pustaka Prossiding/Seminar)

Sugiarso, S.,2004. Pengaruh Jarak Tanam, Dosis Pupuk Urea, dan Jenis Tanah terhadap Produksi Herba Sambiloto ( Andrographis paniculata Ness) Untuk Mendukung Pengadaan Bahan Baku Standar.

http://digilib.litbang,depkes.go.id (Informasi internet)

Winarto, 2003. Sambiloto Budidaya Dan Pemanfaatan untuk Obat. Penebar Swadaya Jakarta. (Pustaka buku)

Widowati, L. 2007. .Penyediaan Granul Ekstrak Sambiloto Sebagai Fitofarmaka Antidiabetik Oral. http://digilib.litbang.depkes.go.id diakses 13 Juli 2007.(Informasi internet) Widyawati, T. 2007. Aspek Farmakologi Sambiloto (Andrographis paniculata Ness). Majalah Kedokteran Nusantara Volume $40 \quad$ No.3 September 2007.(Pustaka Jurnal)

Yusron, M. Dan M. Januwati, 2004. Pengaruh Kondisi Argoekologi terhadap Produksi dan Mutu Simplisia Sambiloto (Andrographis paniculata Ness.) Pros. Seminar Nasional Tumbuhan Obat Indonesia. XXVI. Pokjarnas Tanaman Obat Indonesia. 211-231. (Pustaka Prossiding/Seminar) 